\title{
DAMPAK KUALITAS KEHIDUPAN KERJA DAN MOTIVASI KERJA PADA EMPLOYEE ENGAGEMENT
}

Submitted Date :

21 Oktober 2020

Accepted Date :

8 Februari 2021
Fatmasari Endayani

Univesitas Merdeka Malang

fatmasari.endayani@unmer.ac.id

Saman

Univesitas Merdeka Malang azizsaman66@gmail.com

\section{Suggested Citation:}

Mosadeghard, Ali Mohammad. (2013). Quality of Working Life : An Antecedent to Employee Turnover Intention. International Journal of Health Policy and Management. Vol. 1(x), 1-10. Iran: Tehran University of Medical Sciences.

\begin{abstract}
:
This study aims to analyze the level of Employee Engagement in education personnel at Merdeka University Malang and another factors related to quality of work life and work motivation. This research was followed by 60 employees of Education Staff of Merdeka University Malang. Explanatory research using a quantitative approach was applied in this research. This study explores the phenomenon of organizations that are increasingly responsive to employee needs. This phenomenon happen so that the company does not lose its best people. Yet the issue of stealing employees is still frequently heard. Organizations are competing to retain employees by paying attention to the quality of work life of their employees and providing encouragement in the form of motivation to retain employees. Based on the simultaneous test results, it can be concluded that there is a significant influence between the quality of work life and work motivation on employee engagement. However, in partial testing, it can be concluded that there is no significant effect between the Quality of Work Life variable and the Employee Engagement variable.
\end{abstract}

\section{Keywords: Employee Engagement, Quality Of Work Life, Work Motivation}

\section{Abstrak}

Pada penelitian ini bertujuan untuk menganalisis tingkat Employee Engagement pada tenaga kependidikan Universitas Merdeka Malang dan faktor-faktor yang berperan diantaranya yaitu kualitas kehidupan kerja dan motivasi kerja. Penelitian dilakukan kepada tenaga kependidikan Universitas Merdeka Malang yang berjumlah 60 karyawan. Penelitian ini merupakan penelitian penjelasan (explanatory research) dengan menggunakan pendekatan kuantitatif. Penelitian ini menggali fenomena mengenai perusahaan atau organisasi yang semakin tanggap terhadap kebutuhan karyawan. Hal ini dilakukan agar perusahaan tidak kehilangan orang-orang terbaiknya. Meskipun demikian, isu bajak membajak karyawan masih sering terdengar. Perusahaan berlomba lomba mempertahankan karyawan dengan memperhatikan kualitas kehidupan kerja para karyawan serta memberikan dorongan berupa motivasi untuk mempertahankan karyawan. Berdasarkan hasil uji secara simultan dapat disimpulkan bahwa terdapat pengaruh signifikan antara Kualitas kehidupan Kerja dan motivasi kerja terhadap employee engagement. Namun pada pengujian secara parsial dapat disimpulkan bahwa tidak terdapat pengaruh signifikan antara variabel Kualitas Kehidupan Kerja terhadap variabel Employee Engagement.

Kata kunci: Employee Engagement, Kualitas Kehidupan Kerja, Motivasi Kerja

JEL Classification : M54 


\section{Latar Belakang Penelitian}

Persaingan perguruan tinggi di Indonesia, khususnya di Kota Malang semakin ketat. Mereka berlomba-lomba untuk mendapatkan sumber daya manusia yang bermutu sehingga mampu bersaing di tingkat nasional maupun internasional. Berbagai cara dilakukan oleh perguruan tinggi untuk mencapai tujuan tersebut. Hal ini tidak terlepas dari kualitas kehidupan kerja dan motivasi kerja tenaga kependidikan di perguruan tinggi. Apabila karyawan mempunyai motivasi yang tinggi, diharapkan mereka akan menunjukkan totalitasnya dan loyalitas terhadap lembaga tersebut, namun apabila mereka tidak mempunyai motivasi yang tinggi maka para tenaga kependidikan cenderung menunjukkan kinerja yang kurang optimal. Keadaan seperti ini akan sangat berimbas pada labour turnover perguruan tinggi tersebut.

Universitas Merdeka (UNMER) Malang adalah salah satu perguruan tinggi swasta yang memiliki slogan "The Quality University". Mengacu dengan slogan yang ada, perguruan tinggi tersebut dituntut untuk mampu meningkatkan kualitas lembaga, kualitas sumber daya, serta kualitas para mahasiswanya. Selain itu, Universitas Merdeka Malang merupakan perguruan tinggi swasta ternama dan memiliki Ranking yang tinggi pada BAN-PT sehingga menjadikan UNMER menjadi salah satu objek yang menarik diteliti. Salah satu upaya untuk mencapai tuntutan tersebut adalah meningkatkan berbagai aspek seperti tata kelola sistem pendidikan. Tenaga kependidikan dalam proses pendidikan merupakan tatanan yang paling penting dalam upaya untuk mengelola administrasi pembelajaran bagi peserta didik dalam suatu lembaga perguruan tinggi, sebagai wujud dari administrasi itu sendiri. Dengan adanya Tenaga Kependidikan, berbagai macam urusan mulai dari admistrasi, pengelolaan, pengembangan, pengawasan, dan pelayanan teknis untuk menunjang proses pendidikan pada satuan pendidikan dapat berjalan. Sehingga tenaga kependidikan memiliki peranan penting dalam perguruan tinggi dan perlu di organisir dengan baik. Hal ini perlu dilakukan agar UNMER mampu bersaing dengan Perguruan Tinggi lain di Malang yang juga berlomba-lomba meningkatkan kualitas lembaganya.

Upaya yang dapat dilakukan untuk mendorong semangat kerja sehingga dapat bersaing yaitu dengan menciptakan kualitas kehidupan kerja yang baik dan meningkatkan motivasi karyawannya. Hal ini juga akan berguna sebagai salah satu cara untuk mempertahankan karyawan. Pengelolaan kehidupan kerja yang baik bertujuan untuk meningkatkan daya saing bagi universitas. Kualitas Kehidupan Kerja memiliki perspektif pendekatan manajerial yang menekankan pada faktor-faktor yang mempengaruhi motivasi kerja.

Langkah yang dapat dilakukan untuk memaksimalkan fungsi sumber daya manusia tidak hanya dilakukan dengan memperhatikan kualitas kehidupan kerja yang baik saja, tetapi perlu memperhatikan faktor lain seperti motivasi kerja karyawan. Pemimpin yang baik harus mampu memberikan motivasi kepada karyawannya. Motivasi kerja merupakan suatu dorongan yang ada dalam diri karyawan untuk dapat menyelesaikan tugas dan tanggungjawab yang telah diberikan. Hal ini berarti apabila motivasi karyawan tinggi maka akan berdampak pada peningkatan Employee Engagement.

Penelitian mengenai employee engagement ini didukung dengan adanya beberapa research gap, yaitu penelitian Arif \& llyas (2013) mengungkapkan bahwa secara keseluruhan persepsi kualitas kehidupan kerja berpengaruh terhadap kepuasan akan tetapi tidak berdampak kepada engagement dan komitmen karyawan. Sejalan dan sependapat dengan penelitian yang dilakukan oleh Mehrzi \& Singh (2016) serta Slatten \& Mehmetoglu (2012) yang menemukan bahwa masih sedikitnya penelitian mengenai variabel employee engagement dan perlu dilakukan eksplorasi terkait variabel tersebut untuk penelitian selanjutnya.

Ada beberapa alasan yang melatar belakangi penulis dalam memilih topik penelitian ini. Pertama, sejalan dengan temuan beberapa research gap mengenai kualitas kehidupan kerja, motivasi kerja, dan employee engagement, maka perlu adanya penelitian lanjutan mengenai hal tersebut. Kedua, peranan tenaga kependidikan terhadap mahasiswa dalam suatu Universitas merupakan faktor penting terhadap penyelenggaran tridarma pendidikan tinggi, di dalam tata kelola administrasi. Ketiga, mengacu pada masalah pembajakan karyawan yang marak terjadi saat ini, sangatlah penting suatu pendidikan tinggi mengetahui tingkat engagement karyawannya. Apabila employee engagement tidak diperhatikan, maka akan menjadi peluang besar bagi Perguruan Tinggi lain untuk menarik mereka ke lembaganya. Hal ini dapat menjadi ancaman untuk kelangsungan hidup pihak Universitas. Berdasarkan hal yang telah diuraikan sebelumnya, maka peneliti dapat merumuskan tujuan penelitian ini adalah untuk menguji dan menganalisis pengaruh peningkatan kualitas kehidupan kerja dan motivasi kerja yang berdampak pada employee engagement. 


\section{Literature Review}

\section{Konsep Kualitas Kehidupan Kerja}

Kualitas kehidupan kerja merupakan suatu kondisi atau keadaan sebagai hasil dari interaksi antara individu dan pekerjaannya yang dapat membuat karyawan lebih produktif dan menimbulkan kepuasan kerja. Kualitas kehidupan kerja merupakan komponen yang perlu diterapkan dalam organisasi. Konsep ini memandang hubungan antara manajemen, karyawan, dan organisasi. Mosadeghard (2013) yang menjelaskan mengenai kualitas kehidupan kerja yaitu meningkatkan martabat karyawan melalui kepuasan kerja dan memanusiakan pekerjaan dengan menetapkan pekerjaan yang bermakna, memberikan kesempatan untuk berkembang, menjamin keamanan kerja, gaji dan tunjangan yang memadai, dan menyediakan kondisi kerja yang aman dan sehat

\section{Konsep Motivasi Kerja}

Self-Determination Theory (SDT) adalah sebuah pendekatan motivasi dan kepribadian manusia yang menggunakan metode empiris tradisional dengan menggunakan meta teori organismic yang menyoroti pentingnya sumber daya manusia untuk pengembangan kepribadian dan perilaku regulasi diri. Ryan \& Deci (2010) mendefinisikan determinasi diri sebagai "menyelidiki kecenderungan pertumbuhan yang melekat pada seseorang dan bawaan kebutuhan psikologis dasar untuk motivasi diri dan integrasi kepribadian". Teori ini menekankan pentingnya sumber daya manusia untuk melakukan pengembangan kepribadian dan regulasi diri.

Pada dasarnya teori ini menyangkut tentang regulasi dari perilaku dan faktor-faktor yang mempengaruhi regulasi tersebut. Individu sering merasakan kekurangan motivasi dalam melakukan pekerjaan dikarenakan hambatan-hambatan dalam melakukannya. Berdasar Self-Determination Theory, ada beberapa jenis tipe motivasi yang berada dalam sebuah kontinum/ rangkaian, yaitu: amotivation, extrinsic motivation yang dapat dibagi lagi menjadi empat jenis (external regulation, introjected regulation, identified regulation, integrated regulation), dan intrinsic motivation. Pada penelitian ini, alat ukur motivasi kerja didasarkan pada self-determnintion theory.

\section{Konsep Employee Engagement}

Keterlibatan karyawan (Employee Engagement) adalah suatu fenomena yang harus diperhatikan seorang manajer dalam lingkungan bisnisnya. Employee Engagement merupakan aspek penting bagi perusahaan untuk meningkatkan kinerja. Engagement diartikan sebagai status "keterikatan" (dalam arti positif) seorang Karyawan tehadap lingkungan kerja atau perusahaan tempatnya bekerja.

Employee Engagement pertama kali dikonseptualisasian oleh Kahn (1990) sebagai keadaan dimana anggota organisasi mengidentifikasi dirinya dengan pekerjaanya. Dalam engagement, seseorang akan mempekerjakan dan mengespresikan diri mereka secara fisik, kognitif, dan emosional selama menunjukkan kinerja mereka. Employee Engagement dicirikan oleh karyawan yang percaya pada apa yang diyakininya dan bersedia untuk melampaui batasan-batasan kontrak tertulis karena employee engagement lebih menekankan pada kontrak secara psikologis. Employee Engagement mencakup aspek think, feels, dan doing. Dapat disimpulkan bahwa Employee Engagement adalah suatu komitmen karyawan yang didasari oleh sifat emosional seperti antuasiasme dan rela memberikan usaha lebih besar untuk membesarkan nama perusahaan. Engagement merupakan bentuk kesadaran yang dimiliki karyawan tanpa dipengaruhi oleh hal tertentu dan bersifat secara terus menerus. Hal ini dapat membantu organisasi dalam mencapai tujuannya.

\section{Metode Penelitian}

Penelitian ini menggunakan jenis penelitian kuantitatif, yaitu jenis penelitian yang menggunakan rancangan penelitian berdasarkan prosedur statistik atau dengan cara lain dari kuantifikasi untuk mengukur variabel penelitiannya. Penelitian ini merupakan penelitian penjelasan (explanatory research). Penelitian ini menggunakan teknik sampling jenuh dan diperoleh sampel sebanyak 60 orang yang merupakan Tenaga Kependidikan di lingkungan Universitas Merdeka Malang. Pengumpulan data dilakukan dengan memberikan kuesioner kepada responden. Sumber data penelitian terdiri atas data primer dan sekunder. Teknik analisis data yang digunakan di dalam penelitian ini adalah regresi linear berganda. 
Hasil

Hasil model analisis regresi linear berganda adalah sebagai berikut :

Tabel 1. Hasil Analisis Regresi Linear Berganda

\begin{tabular}{|c|c|c|c|c|c|c|}
\hline \multicolumn{7}{|c|}{ Coefficients ${ }^{\mathrm{a}}$} \\
\hline \multirow{2}{*}{\multicolumn{2}{|c|}{ Model }} & Unstandardize & Coefficients & $\begin{array}{c}\text { Standardized } \\
\text { Coefficients }\end{array}$ & & \\
\hline & & $B$ & Std. Error & Beta & $\mathrm{T}$ & Sig. \\
\hline \multirow[t]{3}{*}{1} & (Constant) & 17.478 & 5.340 & & 3.273 & .002 \\
\hline & $\begin{array}{l}\text { Kualitas Kehidupan } \\
\text { Kerja }\end{array}$ & .125 & .071 & .214 & 1.747 & .086 \\
\hline & Motivasi Kerja & .462 & .133 & .427 & 3.487 & .001 \\
\hline
\end{tabular}

Sumber: Hasil Penelitian, 2020 (Data diolah)

Nilai konstanta (a) sebesar 17,478 menunjukkan tanpa adanya pengaruh dari kualitas kehidupan kerja $\left(X_{1}\right)$ dan motivasi kerja $\left(X_{2}\right)$ maka nilai employee engagement $(Y)$ adalah 17,428. Nilai koefisien kualitas kehidupan kerja $\left(X_{1}\right)$ sebesar 0,125 menunjukkan adanya pengaruh positif antara kualitas kehidupan kerja $\left(X_{1}\right)$ terhadap employee engagement $(\mathrm{Y})$, Hal ini berarti setiap peningkatan nilai kualitas kehidupan kerja $\left(\mathrm{X}_{1}\right)$ akan berpengaruh terhadap peningkatan nilai prediksi employee engagement $(Y)$. Hal ini berarti semakin tinggi kualitas kehidupan kerja $\left(\mathrm{X}_{1}\right)$ akan berpengaruh terhadap semakin tinggi employee engagement $(\mathrm{Y})$.

Nilai koefisien motivasi kerja $\left(X_{2}\right)$ sebesar 0,462 menunjukkan adanya pengaruh positif antara motivasi kerja $\left(\mathrm{X}_{2}\right)$ terhadap employee engagement $(\mathrm{Y})$, artinya setiap peningkatan nilai motivasi kerja $\left(\mathrm{X}_{2}\right)$ akan berpengaruh terhadap peningkatan nilai prediksi employee engagement $(\mathrm{Y})$. Hal ini berarti semakin tinggi motivasi kerja $\left(\mathrm{X}_{2}\right)$ akan berpengaruh terhadap semakin tinggi employee engagement $(\mathrm{Y})$.

Selanjutnya, Uji t atau uji parsial menjelaskan ada tidaknya pengaruh antara variabel bebas Kualitas Kehidupan kerja $\left(X_{1}\right)$ dan Motivasi Kerja $\left(X_{2}\right)$ terhadap variabel terikat Employee Engagement $(Y)$ secara individu (parsial). Berikut disajikan hasil pengujian pengaruh secara parsial dengan menggunakan uji t.

Uji parsial antara variabel Kualitas Kehidupan Kerja $\left(\mathrm{X}_{1}\right)$ terhadap variabel Employee Engagement $(\mathrm{Y})$ didapatkan nilai thitung $(1,747)$ kurang dari $t$ tabel $(2,002)$ atau nilai signifikansi $(0,086)$ lebih dari alpha $(0,050)$ sehingga tidak terdapat pengaruh signifikan antara variabel Kualitas Kehidupan Kerja $\left(\mathrm{X}_{1}\right)$ terhadap variabel Employee Engagement (Y).

Uji parsial antara variabel Motivasi Kerja $\left(\mathrm{X}_{2}\right)$ terhadap variabel Employee Engagement $(\mathrm{Y})$ didapatkan nilai t hitung $(3,487)$ lebih dari t tabel $(2,002)$ atau nilai signifikansi $(0,001)$ kurang dari alpha $(0,050)$ sehingga terdapat pengaruh signifikan antara variabel motivasi kerja $\left(\mathrm{X}_{2}\right)$ terhadap variabel Employee Engagement $(\mathrm{Y})$.

Pengujian hipotesis dijabarkan menggunakan uji simultan (uji F), koefisien determinasi $\left(R^{2}\right)$, dan uji parsial (uji t). Uji $F$ atau uji simultan menjelaskan ada tidaknya pengaruh antara variabel bebas kualitas kehidupan kerja $\left(X_{1}\right)$ dan motivasi kerja $\left(\mathrm{X}_{2}\right)$ terhadap variabel terikat employee engagement $(\mathrm{Y})$ secara bersama-sama (simultan). Berikut disajikan hasil pengujian pengaruh secara simultan dengan menggunakan uji $\mathrm{F}$ :

Tabel 2. Uji Simultan (Uji F)

\begin{tabular}{|c|c|c|c|c|c|c|}
\hline \multicolumn{7}{|c|}{ ANOVA $^{b}$} \\
\hline Model & & Sum of Squares & df & Mean Square & $\mathrm{F}$ & Sig. \\
\hline 1 & Regression & 263.032 & 2 & 131.516 & 12.681 & $.000^{\mathrm{b}}$ \\
\hline & Residual & 591.151 & 57 & 10.371 & & \\
\hline & Total & 854.183 & 59 & & & \\
\hline
\end{tabular}

a. Predictors: (Constant), Kualitas Kehidupan Kerja, Motivasi Kerja

a. Dependent Variable: Employee Engagement

Sumber : Hasil Penelitian, 2020 (Datadiolah)

Hasil pengujian secara simultan dengan uji $F$ didapatkan nilai $F$ hitung $(12,681)$ lebih dari $F$ tabel $(3,159)$ atau nilai signifikansi $(0,000)$ kurang dari alpha $(0,050)$ menunjukkan terdapat pengaruh signifikan antara Kualitas kehidupan Kerja $\left(X_{1}\right)$ dan motivasi kerja $\left(X_{2}\right)$ terhadap employee engagement $(Y)$ secara simultan.

Selanjutnya Koefisien determinasi menjelaskan seberapa besar kemampuan variabel bebas dalam menerangkan variasi variabel terikat. Nilai koefisien determinasi yang semakin besar atau mendekati satu menunjukkan semakin besar kemampuan variabel bebas dalam menerangkan variasi variabel terikat. Berikut disajikan hasil koefisien determinasi dengan menggunakan $\mathrm{R}^{2}$. 
Tabel 3 Uji Koefisien Determinasi

\begin{tabular}{ccccc}
\hline Model & $\mathrm{R}$ & R Square & Adjusted R Square & Std. Error of the \\
& & & & Estimate \\
1 & .555 & .308 & .284 & 3.2204
\end{tabular}

a. Predictors: (Constant), Kualitas Kehidupan Kerja, Motivasi Kerja

b. Dependent Variable: Employee Engagement Sumber

Hasil Penelitian, 2020(Data diolah)

Hasil koefisien determinasi didapatkan nilai $R^{2}$ sebesar 0,308 artinya bahwa besar pengaruh terhadap variabel Employee Engagement $(\mathrm{Y})$ yang dijelaskan oleh variabel Kualitas Kehidupan Kerja $\left(\mathrm{X}_{1}\right)$ dan Motivasi Kerja $\left(\mathrm{X}_{2}\right)$ adalah sebesar 30,8 persen, sedangkan sisanya sebesar $69,2 \%$ dijelaskan oleh faktor atau variabel lain yang tidak diteliti dalam penelitian ini. Variabel tersebut antara lain budaya oragnisasi, reward, dan personal resources.

\section{Pembahasan}

\section{Pengaruh Kualitas Kehidupan Kerja Terhadap Employee Engagement}

Hasil dari perhitungan pengujian hipotesis secara parsial variabel Kualitas kehidupan Kerja $\left(X_{1}\right)$ terhadap variable Employee Engagement $(Y)$ diperoleh nilai t hitung $(1,747)$ kurang dari t tabel $(2,002)$ atau nilai signifikansi $(0,086)$ lebih dari alpha $(0,050)$. Hal ini menunjukkan bahwa tidak terdapat pengaruh signifikan antara variabel Kualitas Kehidupan Kerja $\left(X_{1}\right)$ terhadap variabel Employee Engagement $(Y)$. Hal ini terjadi karena kualitas kehidupan kerja berdampak pada variabel lain yang tidak diteliti pada penelitian ini. Namun Hubungan Kualitas Kehidupan kerja dengan employee engagement dapat diperkuat adanya social exchange theory yang dikemukakan oleh Kelley \& Thibault (1978). Dalam social exchange theory disebutkan bahwa adanya hubungan timbal balik dan saling bergantung. Hasil penelitian ini sejalan dengan peneltian yang dilakukan oleh Arif dan llyas (2013) yang menyatakan bahwa Kualitas Kehidupan Kerja tidak berdampak pada employee engagement, akan tetapi berpengaruh terhadap kepuasan kerja. Teori ini mengemukakan bahwa kontribusi seseorang dalam suatu hubungan, di mana hubungan tersebut dapat mempengaruhi kontribusi orang lain. Sebagai contoh, apabila Universitas Merdeka Malang dapat menjamin Kualitas Kehidupan Kerja para Tenaga kependidikan, maka mereka akan cenderung engaged dengan Institusi tersebut.

Kualitas kehidupan kerja tidak hanya berkontribusi pada kemampuan perusahaan untuk meningkatkan kualitas Tenaga Kependidikan akan tetapi juga menjadikan Perguruan Tinggi menjadi lebih kompetitif. Perguruan Tinggi akan lebih fleksibel, membuat Tenaga Kependidikan lebih loyal, sehingga dapat digunakan sebagai kekuatan bersaing dari organisasi dan meningkatkan kualitas sumber daya manusia meliputi pelatihan, seleksi karyawan, dan pengukuran persepsi kinerja karyawan. Selain itu peningkatan kualitas kehidupan kerja akan membawa pengaruh positif terhadap organisasi seperti meningkatkan produktivitas dan menurunkan tingkat absensi dan perputaran karyawan.

\section{Pengaruh Motivasi Kerja Terhadap Employee Engagement}

Hasil perhitungan pengujian hipotesis secara parsial variabel Motivasi Kerja $\left(\mathrm{X}_{2}\right)$ terhadap variable Employee Engagement $(Y)$ didapatkan nilai t hitung $(3,487)$ lebih dari t tabel $(2,002)$ atau nilai signifikansi $(0,001)$ kurang dari alpha $(0,050)$ sehingga terdapat pengaruh signifikan antara variabel motivasi kerja $\left(\mathrm{X}_{2}\right)$ terhadap variabel Employee Engagement $(Y)$. Pengaruh langsung motivasi kerja terhadap employee engagement sejalan dengan penelitian yang dilakukan oleh Mehrzi \& Singh (2016) yang menunjukkan bahwa adanya motivasi karyawan juga berpengaruh terhadap employee engagement. Penelitian tersebut dilakukan di Universitas Abu Dhabi. Pada penelitian ini dihasilkan nilai koefisien beta sebesar 0,221 , dan berarti bahwa motivasi kerja berpengaruh langsung terhadap employee engagement.

Robbins dan Judge (2007) menjelaskan bahwa employee engagement merupakan sebuah keterlibatan individual karyawan, kepuasan, dan antusiasme untuk melakukan pekerjaannya. Pada penelitian ini Tenaga Kependidikan memiliki motivasi kerja yang tinggi. Hal ini mendorong para Tenaga Kependidikan memiliki engagement yang tinggi. Para Tenaga Kependidikan yang mempunyai engagement yang tinggi cenderung memiliki motivasi dan loyalitas yang tinggi terhadap universitas tersebut. 


\section{Kesimpulan}

Berdasarkan hasil dan pembahasan mengenai pengujian secara simultan dapat disimpulkan bahwa terdapat pengaruh signifikan antara Kualitas kehidupan Kerja dan motivasi kerja terhadap employee engagement. Namun pada pengujian secara parsial dapat disimpulkan bahwa tidak terdapat pengaruh signifikan antara variabel Kualitas Kehidupan Kerja terhadap variabel Employee Engagement. Akan tetapi, hasil pengujian parsial pada variable motivasi kerja dapat disimpulkan bahwa terdapat pengaruh signifikan antara variabel motivasi kerja terhadap variabel Employee Engagement.

Variabel motivasi kerja yang memiliki pengaruh lebih besar terhadap variabel employee engagement. Sedangkan pada varibel kualitias kehidupan kerja masih didapatkan skor rendah. Hal ini dapat menjadi pertimbangan untuk pihak Universitas agar lebih memperhatikan kualitas kehidupan kerja para Tenaga Kependidikan, salah satunya dengan cara meninjau ulang pemberian gaji atau remunerasinya sehingga dapat meningkatkan employee engagement.

Selain itu, pada penelitian ini variabel kualitas dan kehidupan kerja dan motivasi karyawan hanya memberikan pengaruh sebesar 30,8 persen. Kemudian sisanya dapat dijelaskan oleh faktor-faktor lain yang tidak diteliti dalam penelitian ini. Mengingat variabel bebas dalam penelitian ini merupakan hal yang sangat penting dalam mempengaruhi Employee Engagement diharapkan hasil penelitian ini dapat dipakai sebagai acuan bagi peneliti selanjutnya untuk mengembangkan penelitian ini dengan mempertimbangkan variabel-variabel lain seperti Budaya Organisasi, Kompensasi, atau Kepemimpinan yang merupakan variabel lain diluar variabel yang sudah masuk dalam penelitian ini. Adanya keterbatasan penelitian dengan menggunakan kuesioner yaitu terkadang jawaban yang diberikan oleh responden tidak menunjukkan keadaan yang sesungguhnya atau cenderung memberikan jawaban yang baik-baik saja (bias). Hal ini bisa terjadi karena adanya karakteristik responden yang berbeda-beda sehingga menyebabkan jawaban bias.

Berdasarkan hasil penelitian ini disarankan bahwa pemberian motivasi intrinsik maupun ekstrinsik perlu untuk terus diperhatikan guna menciptakan adanya semangat kerja sehingga akan berdampak pada keterlibatan Tenaga Kependidikan pada Universitas tersebut. Pekerjaan sebagai Tenaga Kependidikan telah menjadi bagian dari hidup mereka, hal ini mendorong para Tenaga Kependidikan memiliki engagement yang tinggi.

\section{Daftar Pustaka}

Arif, Seema \& Maryam, llyas. (2013). "Quality of work life model for teachers of private universities in Pakistan". Journal of Quality Assurance in education. Emerald Group Publishing Limited. Vol. 21 No. 3, 2013, pp 282298.

Kahn, W.A. (1990). Psychological conditions of personal engagement and disengagement at work. Academy of Management Journal, 33(4), 692-724.

Kahn, W.A. (1990). Psychological conditions of personal engagement and disengagement at work. Academy of Management Journal, 33(4), 692-724.

Kelley, H.H. \& Thibaut, J.W.(1978). Interpersonal Relations: A Theory of Interdependence. New York: Wiley

Mehrzi, Nada \& Singh, Sanjay Kumar. (2016). Competing through employee engagement: a proposed framework. International Journal of Productivity and Performance Management. Emerald Group Publoshing Limited. Vol. 65 №. 6, 2016 pp. 831-843

Mosadeghard, Ali Mohammad. (2013). Quality of Working Life : An Antecedent to Employee Turnover Intention. International Journal of Health Policy and Management. Vol. 1(x), 1-10. Iran: Tehran University of Medical Sciences.

Robbbins dan Judge. (2007). Perilaku Organisasi, Buku 1 dan 2. Jakarta : Salemba Empat

Ryan, R.M. and Deci, E.L. (2000). Self-determination theory and the facilitation of intrinsic motivation, social development, and well-being. American Psychologist, Vol. 55 No. 1, pp. 68-78.

Slatten, Terje \& Mehmetoglu, Mehmet. (2012). Antecedents and effects of engaged frontline employees A study from the hospitality industry. Managing Service Quality. Emerald Group Publishing Limited. Vol. 21 No.1, 2011, pp 88-107 